\title{
Water Purification and Adsorption Ability of Pumice
}

\author{
Betul M. Agirman \\ Southington High School, 720 Pleasant Street, Southington, CT, 06489, USA; b.munise.a@gmail.com
}

ABSTRACT: Many places in the United States have the problems of heavy metal contamination in their waters. New Jersey,
for example, is facing problems with arsenic and other metals found in tap water, causing the environment to be more polluted and
dangerous for both humans and wildlife. New solutions must be pursued to alleviate this problem. This research project addresses
this topic and presents a possible solution to heavy metal pollution. Pumice, a porous and igneous rock, can possibly act as an
adsorbent to heavy metals such as copper nitrate. In this study, the adsorption capability of pumice was tested, in which different
amounts of pumice were added to deionized water solutions with a fixed amount of copper nitrate. After several days, the solutions
are tested to see if any remaining pumice was present in the water solutions. It was found that pumice does have the capability to
purify water. The results show that certain samples purified water completely. Future studies can be conducted to see how different
brands of pumice purify water along with how different pH's can possibly affect the purification water. KEYWORDS: Earth and Environmental Sciences; Water Science; Heavy Metal Pollution; Pumice; Adsorption.

\section{- Introduction}

The world has been confronted with many issues in the $21^{\text {st }}$ century, beginning at the start of the Industrial Revolution. Environmental issues have been rising and one such issue revolves around water as only $2.5 \%$ of the water on Earth is freshwater and drinkable. Due to infrastructure and other issues, this fresh water gets contaminated with many harmful chemicals. One category of such chemicals is heavy metals. Heavy metals, including arsenic, have been shown to cause cancer and other health issues. ${ }^{1}$

Water is an essential for both human and wildlife; however, heavy metal pollution around the world already decreases what little clean water is already available. Heavy metals can cause negative effects on the human body's immune system, nervous system, and chromosomes and they often contain ions that form complexes with proteins that have carboxylic acid, amine, and thiol groups as attachments. The metal can bind to biological molecules and can inactivate vital enzymes, affecting protein structures, and also affecting certain functions of enzymes in the body. ${ }^{2}$

It can take roughly 40-50 years to fully dispose of heavy metals in the human body. ${ }^{3}$ Moreover, metals the public believes to be simple and harmless such as aluminum can result in Alzheimer's, and/or dementia. Copper nitrate is found in many paints and when it drains into the sea, it can easily poison and kill off marine wildlife. ${ }^{4}$ These metals can easily enter both humans and the ecosystem. They can first enter into fish and physically harm them. Furthermore, metals can then enter humans since fish is a source of protein. ${ }^{5}$ According to the University of Virginia, in the United States, there are 1,305 sites scheduled for cleanup on the National Priorities List. ${ }^{6}$ Heavy metal pollution is dangerous and is a prevalent issue that needs to be resolved.

In this study, a method of adsorbing these heavy metals from water will be explored. Pumice, an igneous rock and porous rock, is presented as a possible solution to this problem.
Pumice is so porous that when put into water, it floats until becoming waterlogged. ${ }^{7}$ Due to these characteristics, pumice is hypothesized to be a potential adsorbent of heavy metals present in water and could be used to purify it.

Essentially, the problem at hand can be surmised into one question; can the porous rock pumice act an adsorbent to heavy metals such as copper nitrate? The goal of this study is to be able to find a potential material that can make water purification not only practical but also affordable.

\section{- Methods}

This experiment was controlled, as variables including temperature, mass of copper nitrate $\left(\mathrm{Cu}\left(\mathrm{NO}_{3}\right)_{2}\right)$, the $\mathrm{pH}$ of the water solutions, the amount of time given for adsorption to occur, and amount of water given to each solution were all held constant across trials. The independent variable being the amount of pumice provided to the water solutions. There were samples with $0 \mathrm{~g}$ (control), $2 \mathrm{~g}, 4 \mathrm{~g}$, or $8 \mathrm{~g}$ in it. Therefore, the dependent variable is the amount of copper nitrate remaining in the water after a period of time given for the pumice to potentially undergo adsorption. This will be measured using both a UV-VIS (Ultraviolet Visible Imaging Spectroscopy) and an EPR (Electron paramagnetic resonance spectroscopy). $42 \mathrm{~g}$ of pumice were required for the entire experiment and the brands SimplyFoot ${ }^{\mathrm{TM}}$ and U.S. Pumice ${ }^{\mathrm{TM}}$ were used. The former pumice brand was a lighter colored rock when compared to the latter. A furnace was required to heat the pumice at $160-170{ }^{\circ} \mathrm{C}$. Then deionized water or water at $\mathrm{pH}$ 7 was required as well for a total of $2400 \mathrm{~mL} .2 .4 \mathrm{~g}$ of copper nitrate, a metal spatula, rock hammer, plastic tray, tin foil, scale (OHAUS ${ }^{\mathrm{TM}}$ ), liquid pipette, 12 beakers, and parafilm were also required. As mentioned, the UV-VIS and EPR devices were also required as well. For the UV-VIS, $1 \mathrm{~cm}$ by $1 \mathrm{~cm}$ by $4 \mathrm{~cm}$ cuvette is required. For the EPR, twelve $50 \mu \mathrm{L}$, micropipette tips, a test tube (that fits exclusively with the EPR), and wax seal were required. Both systems come with a computer 
program that displays how much metal is in a water solution (computer program used is Bruker EMX_nano spectrometer).

Note: the EPR is a magnet that causes the spare electrons on the copper nitrate atoms to flip over, effectively getting a signal from the control over whether there is metal in the water sample or not. The EPR has an $\mathrm{x}$ axis that measures the intensity of the magnetic field in Gauss $(G)$. It has an arbitrary y axis, and thus uses the fundamentals of calculus to determine how many "spins", or electrons are in the sample being scanned by the EPR. The computer program linked to the EPR was able to read the red highlighted area on the signal graphs and see how many "spins" were in the sample, which can be seen in the corresponding chart. The EPR was used to get more accurate data than the UV-VIS, since the signals on that were smaller in comparison to the EPR. Also, the EPR was used since there was an outlier in the $8 \mathrm{~g}$ of pumice water samples data collection from the UV-VIS. The EPR conveyed why this outlier existed, which will be later discussed.

\section{Procedure:}

First, the pumice samples were taken and placed in a furnace at $160-170{ }^{\circ} \mathrm{C}$ for 96 hours. This killed organic impurities in the rock (i.e., microorganisms) that might affect the absorption capability of pumice. After this is done, the pumice samples were left to cool down for one hour. While the pumice cooled, a $0.2 \mathrm{~g}$ sample of copper nitrate was measured and placed in each of the 12 beakers. Then, $200 \mathrm{~mL}$ of deionized ( $\mathrm{pH} 7$ ) water was placed in each beaker. Then the beakers were mixed thoroughly so that the metal dissolved with the water. Afterwards, the pumice was crushed into smaller chunks. The chunks were no larger than $3 \mathrm{~cm}$ by 3 $\mathrm{cm}$ by $3 \mathrm{~cm}$. Three of the beakers did not have any pumice; these beakers were the control variables. Subsequently, another three beakers had $2 \mathrm{~g}$ of pumice each. Then three beakers with $4 \mathrm{~g}$ of pumice each and finally, three beakers with $8 \mathrm{~g}$ of pumice each. All beakers were covered with a 5 in. by 5 in. piece of parafilm. This prevented evaporation of water that could hinder the results of the experiment. Then, the samples were left for 72 hours or more for potential adsorption to occur. The reason for this long wait time was due to the fact that it was unclear as to how much time would be required for adsorption to occur. So, a long-time window was put in place as the purpose of this study was to discover if pumice has adsorption capabilities.

After this waiting period, the UV-VIS was used to measure each beaker's water sample. The UV-VIS essentially measured the samples by using color. The copper nitrate had a blue color, which gave the water a slight blue hue. The UV-VIS works by causing spare electrons on a metal to shift positions. This was what caused color to be seen in the copper nitrate similar to optical density which is the degree to which a refractive medium retards the transmitted rays of light. Then a disposable liquid pipette was used to transfer $1-2 \mathrm{~mL}$ of the water into the cuvette which was then placed into the UV-VIS. This step was repeated for all 12 beakers and the data was saved. This data showed the absorption level, or the amount of light being absorbed by the electrons in the sample, at different wavelengths. Normal, ( $\mathrm{pH} 7$ ) water had no adsorption levels. To see if absorption occurred, the data was compared with the absorption levels of the control with the rest of the samples.

Normally, the data from the UV-VIS would suffice to tell whether adsorption occurred in the solutions with the pumice. However, this particular study went one step further and used the EPR to get a better view of the signal copper nitrate had in water (this was done 120 hours after the beakers were covered by parafilm). The EPR works by causing the spare electron to flip over, measuring the number of electrons flipping over, and thus not needing a colored metal for its effectiveness (this is done with a magnet in the EPR). First, twelve $50 \mu \mathrm{L}$ samples were taken from each beaker. Using the EPR test tube to place the correct amount of solution in each micropipette, the samples were placed in a $4 \mathrm{~mm}$ diameter tube (which could be placed in the test tube in the EPR). The EPR gave a signal that told how much copper nitrate is in the solution. To see if adsorption occurred, the signals were compared the signal found in the control with the rest of the samples.

\section{Results and Discussion}

It is hypothesized that the water solution with $8 \mathrm{~g}$ of pumice will be the most purified of the copper nitrate. This is believed because pumice is very porous, and more of it should be able to completely clean the water of the heavy metals.

To start, an important observation to mention is the fact that the white pumice, upon going through the waiting period, turned a color blue. Figures 1 and 2 show images of all of the water samples:

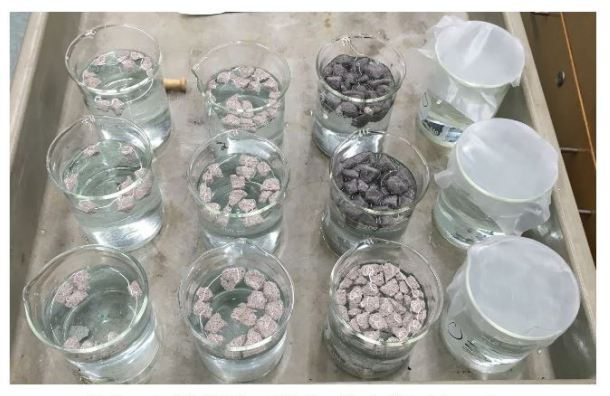

Before the 72-120 hour Waiting Period for Adsorption

Figure 1: All of the water samples before the 72-120 hour absorption waiting period.

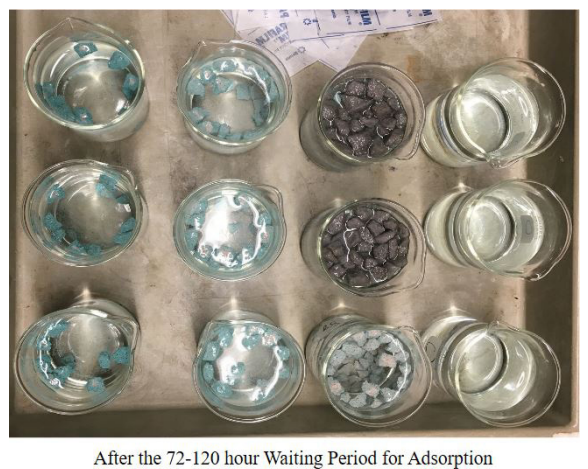

Figure 2: All of the water samples after the 72-120 hour absorption waiting period. 
The reason for this change in color could be directly tied to the adsorption capability of the pumice, especially for the stone white in color. This is due to the fact that adsorption is essentially the attaching of molecules on a surface of a solid, whether that be the outer or inner surfaces of a solid. ${ }^{8}$ In terms of the pumice, since the rock is porous, the copper nitrate adsorbed to both the inner and outer surface of the rock, staining it a color blue. ${ }^{9}$

The results shown by the UV-VIS and EPR also indicate that adsorption did occur for all three of the pumice samples (Tables 1-7, Figures 3-13). The UV-VIS essentially functions by reflecting light on the copper nitrate in water. The remaining light that goes through the system can then be used to calculate how much metal is in the particular solution. ${ }^{10}$ When looking at the UV-VIS absorbance levels at $800 \mathrm{~nm}$, the signal could be seen (Figure 13). $\mathrm{pH} 7$ water has a straight line on the UV-VIS. The control however does not, displaying that there is metal in the water.

When looking at the $2 \mathrm{~g}$ of pumice water samples, the UVVIS data showed that a majority of the metal has been purified from the water. On average, about a decrease in $0.04 \mathrm{OD}$ occurred between the control and the $2 \mathrm{~g}$ of pumice samples, meaning that there was barely any copper nitrate left in the $2 \mathrm{~g}$ of pumice sample. In the $4 \mathrm{~g}$ of pumice water samples, the data shows negative numbers on the UV-VIS. This means that the instrument could not find any other copper nitrate in the solution to absorb the light, which leads to the conclusion that the $4 \mathrm{~g}$ of pumice purified the water completely. The $8 \mathrm{~g}$ of pumice, while not performing as well as the $4 \mathrm{~g}$ of pumice, still adsorbed more than the $2 \mathrm{~g}$ of pumice. Its absorbance difference from the control was $0.044 \mathrm{OD}$, meaning that it still mostly purified the water, similarly the $2 \mathrm{~g}$ of pumice sample. The potential reason for this phenomenon will be fully discussed.

Table 1: Light absorption for heavy metals in the controlled water samples as well as the average absorption for each wavelength.

Light Absorption for Heavy metals in Control Variable Water Samples and Averages

\begin{tabular}{|r|r|r|r|r}
\hline $\begin{array}{l}\text { Wavelengths } \\
\text { (nm) }\end{array}$ & $\begin{array}{l}\text { Sample 1 } \\
\text { Absorption (OD) }\end{array}$ & $\begin{array}{l}\text { Sample 2 } \\
\text { Absorption (OD) }\end{array}$ & $\begin{array}{l}\text { Sample 3 } \\
\text { Absorption (OD) }\end{array}$ & \multicolumn{2}{l}{$\begin{array}{l}\text { Average Absorption } \\
\text { (OD) }\end{array}$} \\
\hline 350.13 & 0.019 & -0.035 & -0.16 & -0.059 \\
\hline 400.03 & -0.105 & -0.107 & -0.049 & -0.087 \\
\hline 450.05 & -0.04 & -0.034 & -0.011 & -0.028 \\
\hline 500.14 & -0.035 & -0.034 & -0.014 & -0.028 \\
\hline 550.02 & -0.035 & -0.032 & -0.01 & -0.026 \\
\hline 600.05 & -0.029 & -0.028 & -0.011 & -0.023 \\
\hline 650.13 & -0.014 & -0.008 & 0.015 & -0.002 \\
\hline 700.01 & -0.001 & 0.011 & 0.026 & 0.012 \\
\hline 750.15 & 0.025 & 0.038 & 0.049 & 0.037 \\
\hline 800.08 & 0.029 & 0.051 & 0.061 & 0.047 \\
\hline 850.05 & 0.026 & 0.047 & 0.032 & 0.035 \\
\hline 900.11 & 0.002 & 0.021 & 0.015 & 0.013 \\
\hline 950.1 & 0.025 & -0.006 & 0.018 & 0.012 \\
\hline 1000.01 & 0.246 & 0.121 & -0.055 & 0.104 \\
\hline
\end{tabular}

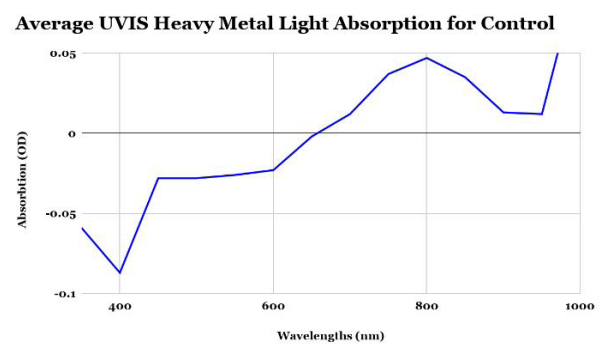

Figure 3: Average UV-VIS heavy metal light absorption for the control group.

Table 2: Light absorption for heavy metals in the $2 \mathrm{~g}$ pumice water samples as well as the average absorption for each wavelength.

Light Absorption for Heavy metals in Water Samples with 2 Grams of Pumice and Averages

\begin{tabular}{|r|r|r|l|r}
\hline $\begin{array}{l}\text { Wavelengths } \\
\text { (nm) }\end{array}$ & $\begin{array}{l}\text { Sample 1 } \\
\text { Absorption (OD) }\end{array}$ & $\begin{array}{l}\text { Sample 2 } \\
\text { Absorption (OD) }\end{array}$ & $\begin{array}{l}\text { Sample 3 } \\
\text { Absorption (OD) }\end{array}$ & $\begin{array}{l}\text { Average Absorption } \\
\text { (OD) }\end{array}$ \\
\hline 350.13 & -0.22 & -0.262 & -0.353 & -0.278 \\
\hline 400.03 & -0.08 & -0.058 & -0.068 & -0.069 \\
\hline 450.05 & -0.031 & -0.021 & -0.019 & -0.024 \\
\hline 500.14 & -0.03 & -0.018 & -0.023 & -0.024 \\
\hline 550.02 & -0.012 & -0.031 & -0.017 & -0.02 \\
\hline 600.05 & -0.012 & -0.028 & -0.022 & -0.021 \\
\hline 650.13 & -0.01 & -0.011 & -0.006 & -0.009 \\
\hline 700.01 & -0.006 & -0.012 & -0.003 & -0.007 \\
\hline 750.15 & 0.001 & -0.003 & 0.006 & 0.001 \\
\hline 800.08 & 0.014 & -0.001 & 0.007 & 0.007 \\
\hline 850.05 & 0.003 & 0.009 & -0.011 & 0 \\
\hline 900.11 & -0.023 & -0.009 & -0.044 & -0.025 \\
\hline 950.1 & -0.066 & $-0.041:$ & -0.099 & -0.069 \\
\hline 1000.01 & -0.139 & -0.277 & -0.18 & -0.199 \\
\hline
\end{tabular}

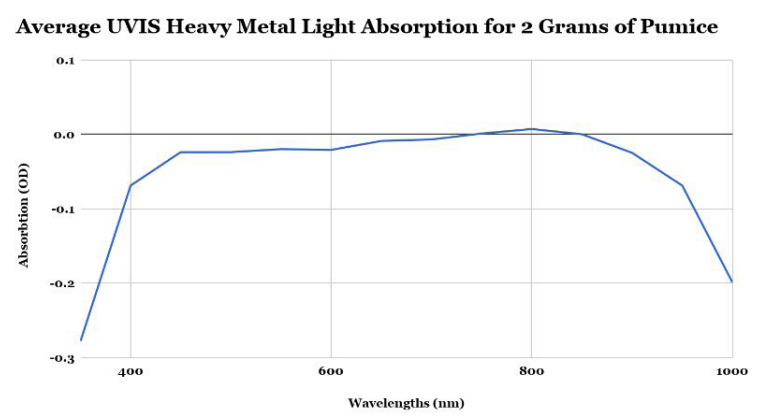

Figure 4: Average UV-VIS heavy metal light absorption for the samples with $2 \mathrm{~g}$ of pumice.

Table 3: Light absorption for heavy metals in the $4 \mathrm{~g}$ pumice water samples as well as the average absorption for each wavelength.

Light Absorption for Heavy metals in Water Samples with 4 Grams of Pumice and Averages

\begin{tabular}{|r|r|r|r|r|}
\hline $\begin{array}{l}\text { Wavelengths } \\
\text { (nm) }\end{array}$ & $\begin{array}{l}\text { Sample 1 } \\
\text { Absorption (OD) }\end{array}$ & $\begin{array}{l}\text { Sample 2 } \\
\text { Absorption (OD) }\end{array}$ & $\begin{array}{l}\text { Sample 3 } \\
\text { Absorption (OD) }\end{array}$ & $\begin{array}{l}\text { Average } \\
\text { Absorption (OD) }\end{array}$ \\
\hline 350.13 & -0.282 & -0.396 & -0.147 & -0.275 \\
\hline 400.03 & -0.07 & -0.179 & 0.231 & -0.006 \\
\hline 450.05 & -0.021 & -0.059 & 0.119 & 0.013 \\
\hline 500.14 & -0.031 & -0.046 & 0.088 & 0.004 \\
\hline 550.02 & -0.041 & -0.015 & 0.011 & -0.015 \\
\hline 600.05 & -0.036 & -0.013 & -0.01 & -0.02 \\
\hline 650.13 & -0.028 & -0.003 & 0.003 & -0.009 \\
\hline 700.01 & -0.029 & -0.003 & 0 & -0.011 \\
\hline 750.15 & -0.025 & 0.002 & 0.001 & -0.007 \\
\hline 800.08 & -0.021 & 0 & 0 & -0.007 \\
\hline 850.05 & -0.024 & 0.02 & -0.062 & -0.022 \\
\hline 900.11 & -0.045 & -0.002 & -0.173 & -0.073 \\
\hline 950.1 & -0.104 & -0.049 & -0.171 & -0.108 \\
\hline 1000.01 & -0.271 & -0.366 & -0.469 & -0.369 \\
\hline
\end{tabular}




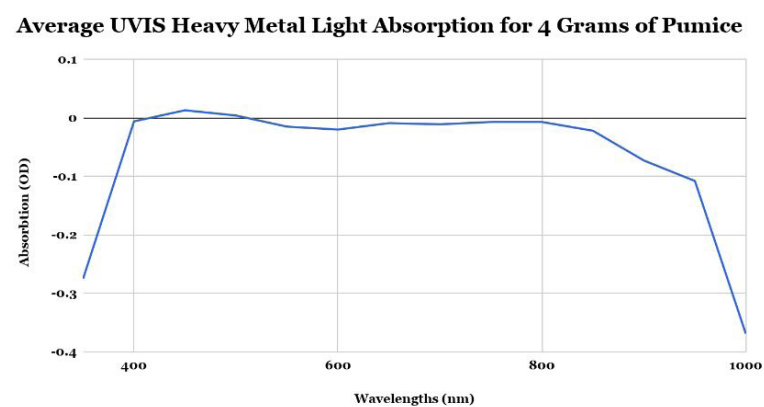

Figure 5: Average UV-VIS heavy metal light absorption for the samples with $4 \mathrm{~g}$ of pumice.

Table 4: Light absorption for heavy metals in the $8 \mathrm{~g}$ pumice water samples as well as the average absorption for each wavelength.

Light Absorption for Heavy metals in Water Samples with 8 Grams of Pumice and Averages

\begin{tabular}{|r|r|r|r|r|}
\hline $\begin{array}{l}\text { Wavelengths } \\
\text { (nm) }\end{array}$ & $\begin{array}{l}\text { Sample 1 } \\
\text { Absorption (OD) }\end{array}$ & $\begin{array}{l}\text { lample 2 } \\
\text { Absorption (OD) }\end{array}$ & $\begin{array}{l}\text { Sample 3 } \\
\text { Absorption (OD) }\end{array}$ & $\begin{array}{l}\text { Average } \\
\text { Absorption (OD) }\end{array}$ \\
\hline 350.13 & -0.407 & -0.474 & -0.361 & -0.414 \\
\hline 400.03 & -0.073 & -0.009 & 0.264 & 0.061 \\
\hline 450.05 & -0.036 & -0.007 & 0.133 & 0.03 \\
\hline 500.14 & -0.04 & -0.013 & 0.088 & 0.012 \\
\hline 550.02 & -0.025 & -0.042 & 0 & -0.022 \\
\hline 600.05 & -0.029 & -0.036 & -0.022 & -0.029 \\
\hline 650.13 & -0.021 & -0.026 & -0.009 & -0.019 \\
\hline 700.01 & -0.024 & -0.016 & -0.005 & -0.015 \\
\hline 750.15 & -0.017 & 0.001 & 0.007 & -0.003 \\
\hline 800.08 & -0.014 & 0.011 & 0.012 & 0.003 \\
\hline 850.05 & -0.021 & -0.007 & -0.056 & -0.028 \\
\hline 900.11 & -0.034 & -0.059 & -0.188 & -0.094 \\
\hline 950.1 & -0.093 & -0.068 & -0.155 & -0.105 \\
\hline 1000.01 & -0.238 & -0.131 & -0.525 & -0.298 \\
\hline
\end{tabular}

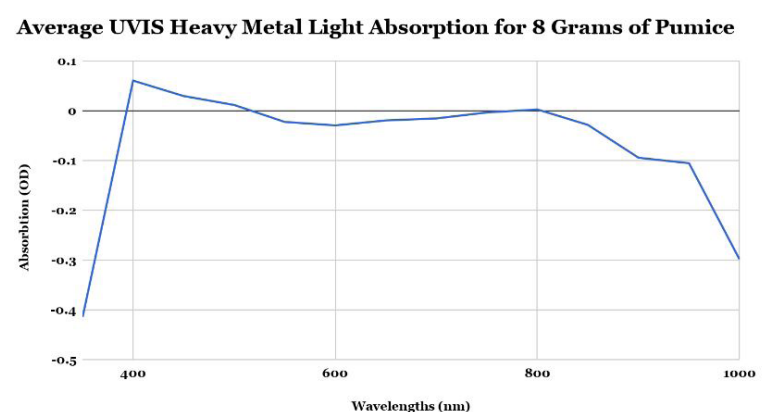

Figure 6: Average UV-VIS heavy metal light absorption for the samples with $8 \mathrm{~g}$ of pumice.

Table 5: Average absorption for each sample at various wavelengths. Average Light Absorption for Heavy metals in All Water Samples

\begin{tabular}{|r|r|r|r|r|}
\hline $\begin{array}{r}\text { Wavelengths } \\
\text { (nm) }\end{array}$ & $\begin{array}{l}\text { Absorption (OD) } \\
\text { For Control }\end{array}$ & $\begin{array}{l}\text { Absorption (OD) For } \\
\text { 2 Grams of Pumice }\end{array}$ & $\begin{array}{l}\text { Absorption (OD) For } \\
\text { 4 Grams of Pumice }\end{array}$ & $\begin{array}{l}\text { Absorption (OD) For } \\
\text { 8 Grams of Pumice }\end{array}$ \\
\hline 350.13 & -0.059 & -0.278 & -0.275 & -0.414 \\
\hline 400.03 & -0.087 & -0.069 & -0.006 & 0.061 \\
\hline 450.05 & -0.028 & -0.024 & 0.013 & 0.03 \\
\hline 500.14 & -0.028 & -0.024 & 0.004 & 0.012 \\
\hline 550.02 & -0.026 & -0.02 & -0.015 & -0.022 \\
\hline 600.05 & -0.023 & -0.021 & -0.02 & -0.029 \\
\hline 650.13 & -0.002 & -0.009 & -0.009 & -0.019 \\
\hline 700.01 & 0.012 & -0.007 & -0.011 & -0.015 \\
\hline 750.15 & 0.037 & 0.001 & -0.007 & -0.003 \\
\hline 800.08 & 0.047 & 0.007 & -0.007 & 0.003 \\
\hline 850.05 & 0.035 & 0 & -0.022 & -0.028 \\
\hline 900.11 & 0.013 & -0.025 & -0.073 & -0.094 \\
\hline 950.1 & 0.012 & -0.069 & -0.108 & -0.105 \\
\hline 1000.01 & 0.104 & -0.199 & -0.369 & -0.298 \\
\hline
\end{tabular}

Comparison of Averages for All Water Samples Tested on UVIS

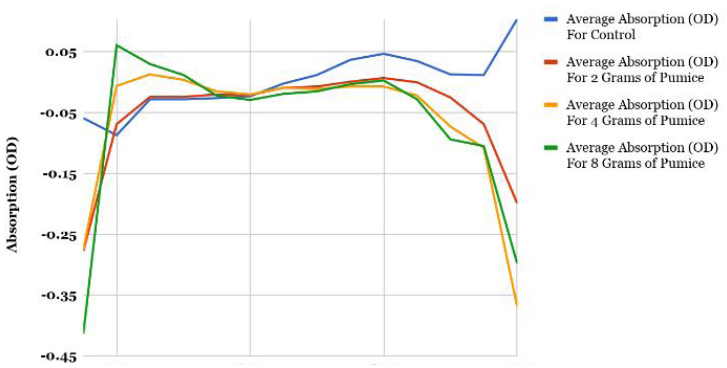

Figure 7: Average UV-VIS heavy metal light absorption for all samples.

Table 6: Average lights absorption for each sample at a wavelength of $800 \mathrm{~nm}$.

Average Light Absorption for Heavy metals in All Water Samples At $800 \mathrm{~nm}$ on UVIS

\begin{tabular}{|l|r|}
\hline Sample Type & Absorption (OD) \\
\hline Control & 0.047 \\
\hline 2 Grams of Pumice & 0.007 \\
\hline 4 Grams of Pumice & 0 \\
\hline 8 Grams of Pumice & 0.003 \\
\hline
\end{tabular}

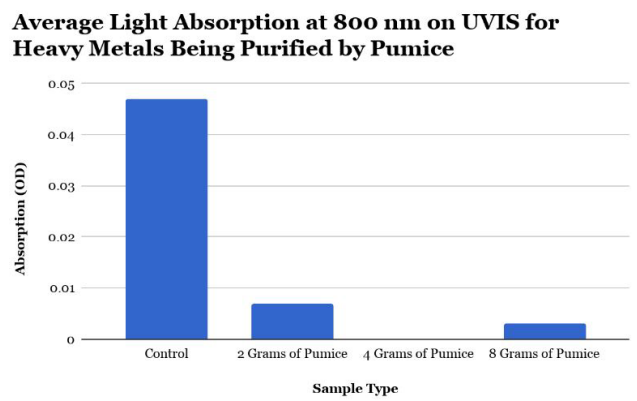

Figure 8: Average absorption of all samples at a wavelength of $800 \mathrm{~nm}$.

Table 7: Number of spins for all water samples, determined from the EPR. EPR Signal \# of Spins Analysis for All Water Samples

\begin{tabular}{|l|r|}
\hline Water Sample Type & \# of Spins \\
\hline Control I & $3.06 \mathrm{E}+16$ \\
\hline Control II & $2.55 \mathrm{E}+16$ \\
\hline Control III & $2.41 \mathrm{E}+16$ \\
\hline 2 grams I & $1.07 \mathrm{E}+15$ \\
\hline 2 grams II & $-3.58 \mathrm{E}+15$ \\
\hline 2 grams III & $-1.29 \mathrm{E}+14$ \\
\hline 4 grams I & $-9.54 \mathrm{E}+14$ \\
\hline 4 grams II & $-2.02 \mathrm{E}+15$ \\
\hline 4 grams III & $-2.10 \mathrm{E}+14$ \\
\hline 8 grams I & $1.27 \mathrm{E}+15$ \\
\hline 8 grams II & $1.10 \mathrm{E}+16$ \\
\hline 8 grams III & $7.58 \mathrm{E}+15$ \\
\hline
\end{tabular}

EPR Signal \# of Spins Analysis Averages for All Water Samples $3.00 \mathrm{E}+16$

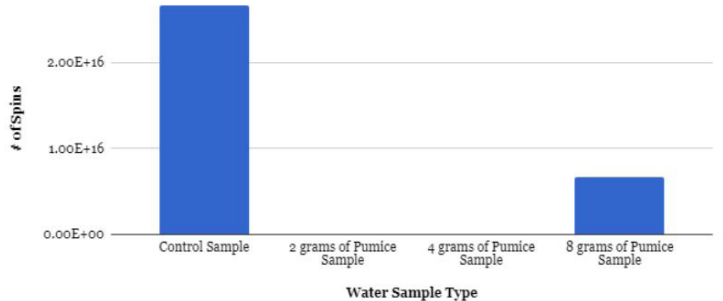

Figure 9: Average number of spins for all water samples determined from the EPR. 
EPR Signal Comparison For Control and 2 Grams of Pumice Water Samples

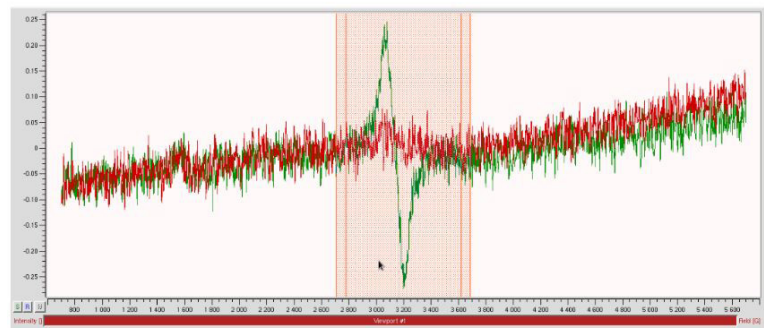

Figure 10: EPR signal comparison of the control and a sample that contained $2 \mathrm{~g}$ of pumice.

EPR Signal Comparison For Control and 4 Grams of Pumice Water Samples

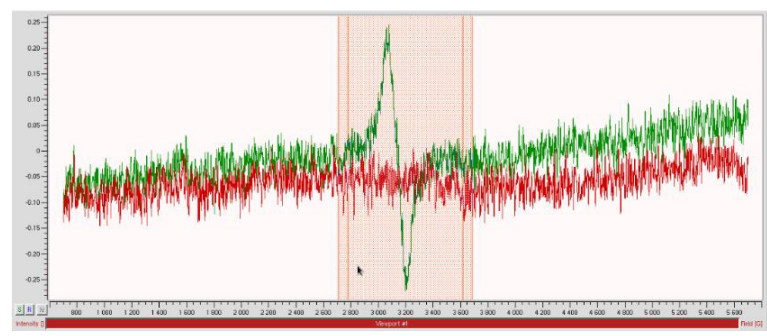

Figure 11: EPR signal comparison of the control and a sample that contained $4 \mathrm{~g}$ of pumice.

EPR Signal Comparison For Control and 8 Grams of Pumice Water Samples (White Pumice)

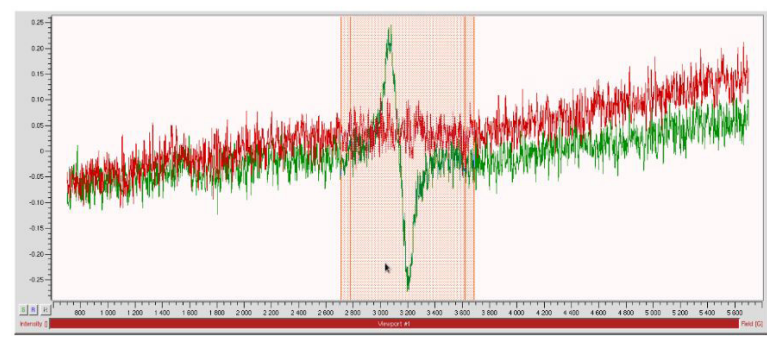

Figure 12: EPR signal comparison of the control and a sample that contained $8 \mathrm{~g}$ of pumice for the white pumice variation.

EPR Signal Comparison For Control and 8 Grams of Pumice Water Samples (Gray Pumice)

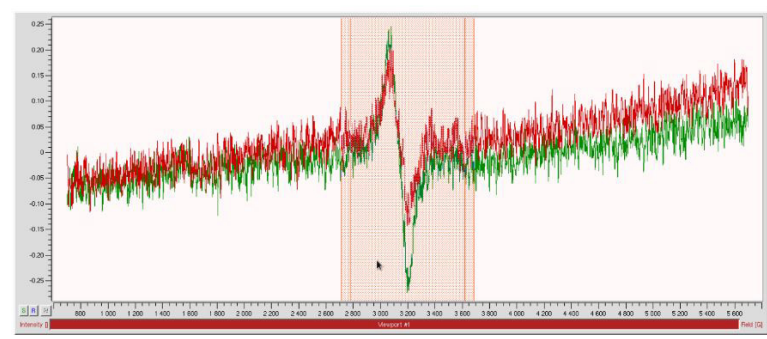

Figure 13: EPR signal comparison of the control and a sample that contained $2 \mathrm{~g}$ of pumice for the gray pumice variation.

The results of the research project show that pumice does indeed act as an adsorbent to heavy metals, particularly for copper nitrate. The hypothesis was somewhat shown to be correct. According to the data, for the UV-VIS, the water sample that contained $4 \mathrm{~g}$ of pumice was the most effective in purifying the water of copper nitrate. Both the UV-VIS and EPR could not detect metal in the samples that were scanned, including their averages. In reality, a negative amount of metal cannot exist in the water, meaning that the UV-VIS and EPR were giving results that suggested that the copper can be detected at $800 \mathrm{~nm}$, when the water sample shows no light absorption at this wavelength, it signifies that there is no more copper nitrate in the solution. For the EPR, the system simply could be so accurate, and will eventually provide a signal that is closer to a signal of neutral $\mathrm{pH}$ water. The sample with $2 \mathrm{~g}$ of pumice got most of the copper nitrate out of the water, and the $8 \mathrm{~g}$ did the same as well, better than the $2 \mathrm{~g}$ sample. However, the sample with $4 \mathrm{~g}$ was most effective at purifying the water.

In the future, if this study is to bring about new innovations in purifying water for both the environment and human use, refinements for future research need to be made. For example, a study on the effectiveness of different pumice rock brands is necessary. As seen in the data for the $8 \mathrm{~g}$ of pumice water samples, the data is slightly skewed to make it appear that while it was effective, it was not as effective the $4 \mathrm{~g}$ of pumice sample. A potential reason for this is the fact that when conducting the experiment, the original white pumice ran out and thus a different brand of gray colored pumice was used to finish up the samples for the $8 \mathrm{~g}$ of pumice. Logically speaking, if the $8 \mathrm{~g}$ of pumice samples all had white pumice just like the 2 and 4-gram samples, they too should have fully purified the water. This data demonstrates that the brand of pumice (i.e., how pumice is treated, color, quality) plays an important role in the rate of adsorption. The gray pumice did still adsorb metal, just not as effectively as its white counterpart. It did not turn blue like the white pumice did (see data analysis and observations for photography of lab setup).

Also, determining how the rate of adsorption is affected in different $\mathrm{pH}$ 's is also another step in this research. In 2015, a similar study had been undertaken by the same experimenter for this study, in which pumice powder was tested at different $\mathrm{pH}$ 's of water with copper nitrate in them. ${ }^{11}$ However, there was no conclusive difference in the water, meaning the pumice powder was not effective in purifying the water by adsorption. The pumice was initially crushed to powder because of the fact that keeping pumice chunks constant is difficult. However, once the original study showed that pumice powder was ineffective as an adsorbent, it was realized that upon crushing the pumice to powder, its porous nature was destroyed. Thus, this study was taken up again in 2018, in which a range was given for the pumice chunk sizes, and it proved effective. In relation to the original study, the idea of $\mathrm{pH}$ affecting adsorption could be explored. Another future study could be measuring pumice adsorption with different types of metals.

Finally, a study on the ratio between the amount of pumice, amount of metal, and amount of water must be tested so the efficiency of pumice can be properly tested.

\section{Conclusion}

This research project concludes that pumice does indeed have the capability to adsorb heavy metals such as copper nitrate. Pumice effectively purified the water of the copper nitrate, opening up the doors for new methods of water purification. The study showed that when a water sample has $0.2 \mathrm{~g}$ of copper nitrate, $4 \mathrm{~g}$ of pumice could purify $200 \mathrm{~mL}$ of water. The $2 \mathrm{~g}$ of pumice also greatly decreased the amount of copper 
nitrate in the water overall. The $8 \mathrm{~g}$ of pumice purified the water more than the sample with $2 \mathrm{~g}$ of pumice but less than the sample with $4 \mathrm{~g}$. Regardless, this study shows that pumice is an adsorbent of heavy metals.

\section{Acknowledgements}

Betul M. Agirman was the sole person that conducted the experiment and researched for this particular project. She was fueled by a personal experience, as one of her colleagues had experienced mercury poisoning in her water. This issue motivated her to find out more about chemistry, environmental sciences, and heavy metal water pollution. Betul Agirman is currently a graduating senior in high school. Ironically enough she is planning to attend the University of Connecticut this coming fall. Dr. Clyde Cady provided use of his laboratory and experimental equipment for this project. Halime Agirman provided transportation during the research and experimentation as transportation from Southington to Storrs, Connecticut was required to conduct the study at the University of Connecticut (UCONN).

\section{References}

1. Dhar, Sanat K. (1973). Metal Ions Biological System. New York: Plenum. Retrieved from http://www.chemistryexplained.com GeHy/Heavy-Metal-Toxins.html\#ixzz58YZcJUlB.

2. Dhar, Sanat K. (1973). Metal Ions Biological System. New York: Plenum. Retrieved from http://www.chemistryexplained.com/ Ge-Hy/Heavy-Metal-Toxins.html\#ixzz58YZcJUlB.

3. Dhar, Sanat K. (1973). Metal Ions Biological System. New York: Plenum. Retrieved from http://www.chemistryexplained. com/Ge-Hy/Heavy-Metal-Toxins.html\#ixzz58YZcJU1B.

4. Copper Nitrate. (2003, February 14).Retrieved June 11, 2018, from https://toxnet.nlm.nih.gov/cgi-bin/sis/search/a?dbs hsdb:@term DOCNO 264.

5. Reyes, Yulieth C., Torres, Omar E. (2016) Water contamination has become a serious problem, since water contaminants -like heavy metalshave increased their concentration during the last century. Retrieved from http://www.journalnano.org/?p=983.

6. Prescott, Noah M. (2009, August 5) Phytoremediation of Heavy Metals.Retrieved from http://faculty.virginia.edu/metals/cases/ prescott3.html.

7. King, Hobart M. (2005-2018). Pumice. Retrieved from http:// geology.com/rocks/pumice.shtml.

8. Adsorption. (2018). In Encyclopædia Britannica. Retrieved from https://school.eb.com/levels/high/article/adsorption/3800.

9. Minerals Education Coalition. (2015-2018). Pumice. Retrieved from https://www.mineralseducationcoalition.org/minerals pumice.

10. National Aeronautics and Space Administration, Science Mission Directorate. (2010).Visible Light. Retrieved [March 1, 2018], from NASA Science website:http://science.nasa.gov/ems/09_ visiblelight.

11. Masoud Moradi, Roshanak Rezaei Kalantary, Touba Khosravi, Hoshmand Sharafi, Kiomars Sharafi. (2015). Equilibrium Isotherms and Kinetic Studies of Lead Removal from Aqueous Solution by Pumice Powder. Retrieved from http://tjeas.com/wp-content/ uploads/2015/03/69-79.pdf

\section{Author}

Betul Agirman, author of this research paper, has recently finished her senior year at Southington High School in Southington, CT. She has passions for research, environmental sciences, and data analysis, which are the main motivators for conducting this research. She plans to continue pursuing research in her future endeavors. 